\title{
APLIKASI JARINGAN SARAF TIRUAN DAN PARTICLE SWARM OPTIMIZATION UNTUK PERAMALAN INDEKS HARGA SAHAM BURSA EFEK INDONESIA
}

\author{
Desy Wartati dan Nur Aini Masruroh \\ Departemen Teknik Mesin dan Industri \\ Universitas Gadjah Mada \\ Email: aini@ugm.ac.id
}

\begin{abstract}
Jakarta Composite Index (JCI) is the main stock index in Indonesia Stock Exchange, which indicates the movement of the performance of all stocks listed. The data of stock price index often experience rapid fluctuations in a short time, so it is needed to carry out an analysis to help investor making the right investment decisions. Forecasting JCI is one of the activities that can be done because it helps to predict the value of the stock price in accordance with the past patterns, so it can be a consideration to make a decision. In this research, there are two forecasting models created to predict JCI, which are Artificial Neural Network (ANN) model with (1) Backpropagation algorithm (BP) and (2) Backpropagation algorithm model combined with Particle Swarm Optimization algorithm (PSO). The development of both models is done from the stage of the training process to obtain optimal weights on each network layer, followed by a stage of the testing process to determine whether the models are valid or not based on the tracking signals that are generated. ANN model is used because it is known to have the ability to process data that is nonlinear such as stock price indices and PSO is used to help ANN to gain weight with a fast computing time and tend to provide optimal results. Forecast results generated from both models are compared based on the error of computation time and forecast error. ANN model with BP algorithm generates computation time of training process for 4,9927 seconds with MSE of training and testing process is respectively 0,0031 and 0,0131, and MAPE of forecast results is 2,55\%. ANN model with BP algorithm combined with PSO generates computation time of training process for 4,3867 seconds with MSE of training and testing process is respectively 0,0030 and 0,0062, and MAPE of forecast result is 1,88\%. Based on these results, it can be concluded that ANN model with BP algorithm combined with PSO provides a more optimal result than ANN model with BP algorithm.
\end{abstract}

Keywords: Artificial Neural Network; Indonesia Stock Exchange; Jakarta Composite Index; Particle Swarm Optimization.

\footnotetext{
ABSTRAK

Dalam pasar saham Bursa Efek Indonesia, Indeks Harga Saham Gabungan (IHSG) merupakan indeks saham utama yang mengindikasikan pergerakan kinerja semua saham yang terdaftar. Data indeks harga saham ini sering mengalami fluktuasi yang cepat dalam waktu yang singkat, sehingga diperlukan suatu analisis agar investor dapat mengambil keputusan investasi yang tepat. Peramalan IHSG merupakan salah satu kegiatan yang dapat dilakukan karena membantu untuk memprediksi nilai harga saham sesuai dengan pola yang terbentuk dari masa lalu, sehingga dapat dijadikan pertimbangan pengambilan keputusan. Pada penelitian ini, terdapat 2 model peramalan yang dibuat untuk memprediksi IHSG, yaitu model Jaringan Saraf Tiruan (JST) dengan algoritma Backpropagation (BP) dan model algoritma Backpropagation yang dikombinasikan dengan algoritma Particle Swarm Optimization (PSO). Pembuatan kedua model dilakukan dari tahap proses pelatihan untuk mendapatkan bobot optimal pada setiap layer jaringan, dilanjutkan dengan tahap proses pengujian untuk mengetahui apakah model yang dibuat sudah valid atau belum berdasarkan tracking signal yang dihasilkan. Adapun pemilihan model JST karena dikenal memiliki kemampuan untuk memproses data yang bersifat nonlinear seperti data indeks harga saham dan PSO digunakan untuk membantu JST mendapatkan bobot dengan waktu komputasi yang cepat dan hasil yang optimal. Hasil peramalan yang dilakukan dengan kedua model yang telah dibuat dibandingkan berdasarkan waktu komputasi, error model,
} 
dan error peramalan. Model JST dengan algoritma BP menghasilkan waktu komputasi proses pelatihan selama 4,9927 detik dengan MSE proses pelatihan dan pengujian masing-masing 0,0031 dan 0,0131, serta MAPE hasil peramalan sebesar 2,55\%. Model JST dengan algoritma BP yang dikombinasikan dengan PSO menghasilkan waktu komputasi proses pelatihan selama 4,3867 detik dengan MSE proses pelatihan dan pengujian masing-masing 0,0030 dan 0,0062 , serta MAPE hasil peramalan sebesar $1,88 \%$. Berdasarkan hasil tersebut, diperoleh bahwa model JST dengan algoritma BP yang dikombinasikan dengan PSO memberikan hasil yang lebih optimal dibandingkan model JST dengan algoritma BP.

Kata Kunci: Backpropagation; Bursa Efek Indonesia; Indeks Harga Saham Gabungan; Jaringan Saraf Tiruan; Particle Swarm Optimization.

\section{PENGANTAR}

Pasar saham merupakan salah satu pilihan investasi yang selalu memiliki daya tarik dari waktu ke waktu (Khirbat $d k k$., 2013). Selain sebagai sarana pendanaan perusahaan, investasi di pasar saham mampu memberikan keuntungan yang menarik bagi para investor. Ketertarikan investor terhadap pasar saham salah satunya terjadi di pasar modal sekaligus pasar saham Indonesia yang dikenal dengan nama Bursa Efek Indonesia (BEI). Hal ini dapat direpresentasikan dari jumlah investor yang tercatat di BEI yang mengalami peningkatan sebanyak 26\% dari Juli 2015 hingga Juli 2016 (Kustodian Sentral Efek Indonesia, 2016). Adanya peningkatan tersebut antara lain disebabkan oleh penerbitan Undang-Undang No.11 Tahun 2016 tentang pengampunan pajak serta sosialisasi dan edukasi pasar modal yang terus dilakukan oleh BEI (Sadono, 2016).

Pada pasar saham, faktor penting yang akan mempengaruhi keputusan investasi adalah harga saham dan pergerakannya. Untuk mengetahui pergerakan harga saham apakah turun, stabil, atau naik maka dibutuhkan indeks harga saham sebagai indikator yang dapat merepresentasikan hal tersebut. Indeks harga saham utama di BEI adalah Indeks Harga Saham Gabungan (IHSG) karena indeks ini merupakan indeks yang mencerminkan kinerja semua saham yang terdaftar.
Indeks harga saham termasuk IHSG sering mengalami fluktuasi yang cepat dalam waktu singkat, sehingga perlu dilakukan analisis untuk membantu investor dalam pertimbangan pengambilan keputusan yang tepat. Salah satu pendekatan yang dapat digunakan adalah analisis teknikal, yaitu suatu pendekatan yang didasarkan pada prinsip Teori Dow yang meramalkan pergerakan indeks harga saham berdasarkan data historis (Kurniawati et al., 2013). Analisis teknikal dapat dilakukan dengan quantitative forecasting models berbasis data time series karena indeks harga saham erat kaitannya dengan data historis, yaitu berkaitan dengan pengaruh nilai masa lalu terhadap nilai masa kini. Time series akan menganalisis pola hubungan antara variabel yang akan diramalkan dengan variabel waktu.

Metode time series yang umum digunakan untuk melakukan peramalan indeks harga saham salah satunya pada IHSG adalah metode Box-Jenkins Autoregressive Integrated Moving Average (ARIMA). Aplikasi ARIMA salah satunya terdapat dalam penelitian Adebiyi et al. (2014) yang melakukan peramalan saham New York Stock Exchange (NYSE) dan Nigeria Stock Exchange (NSE). Pada penelitian tersebut, data yang akan diolah adalah data historis berupa harga saham kedua negara. Harga saham terdiri dari empat unsur, yaitu harga pembuka, harga tertinggi, harga terendah, dan harga penutup. Dari keempat unsur harga saham, harga penutup dipilih untuk diolah karena merupakan data yang dapat merepresentasikan indeks dari semua kegiatan perdagangan. Hasil penelitian menunjukkan bahwa model ARIMA memiliki potensi kuat dalam meramalkan saham untuk jangka pendek. Penelitian lain (Banarjee, 2014) menggunakan ARIMA dalam peramalan Indian Stock dan menghasilkan ARIMA $(1,0,1)$ sebagai model terbaik. Model ARIMA yang dihasilkan tidak bisa digunakan jika sewaktu-waktu terjadi fluktuasi pada data yang digunakan karena model tidak dapat mengakomodasi adanya perubahan pola data. Selain model yang tidak robust, data yang diolah diasumsikan linear sedangkan pada kenyataannya hal tersebut sangat jarang 
terjadi. Oleh sebab itu, ketika menggunakan model untuk meramalkan data dengan pola nonlinear hasil yang diperoleh menjadi tidak efektif.

Penggunaan metode ARIMA fokus pada data empiris yang bersifat normal, linear, dan diasumsikan stasioner (Chen, 1994). Metode ini tidak dapat mengolah suatu data runtun waktu dengan variabilitas yang tinggi sehingga tidak efektif untuk meramalkan indeks harga saham yang bersifat random, nonlinear dan nonstasioner. Berdasarkan hal tersebut, beberapa penelitian selanjutnya mengkombinasikan metode ARIMA dengan Support Vector Machine untuk meminimalisir resiko dari data yang fluktuatif.

Support Vector Machine (SVM) merupakan algoritma pembelajaran yang berbasis teori pembelajaran statistik yang diperkenalkan oleh Cortes dan Vapnik (1995). SVM berfungsi mengklasifikasikan dua set data dari kelas yang berbeda secara efisien dengan memetakan data dari dimensi yang rendah ke dimensi yang tinggi menggunakan nonlinear kernel function (Devi $d k k .$, 2015). Salah satu aplikasi yang mengkombinasikan ARIMA dengan SVM adalah pada penelitian Sirijunyapong et al. (2014) yang melakukan peramalan pada Bursa Efek Thailand. Peramalan saham fokus pada sektor keuangan tiga bank penting Thailand yaitu Bangkok Bank Public Company Limited (BBL), Siam Commercial Bank Public Company Limited (SCB), dan Kasikornbank Public Company Limited. Semua data terkait harga saham ketiga bank didapatkan dari Smart Portal (Version 4.6.1). Data tersebut berubah setiap hari dikarenakan faktor ekonomi, politik dan gross domestic product. Berdasarkan informasi tersebut, diperoleh bahwa terdapat faktor eksternal yang tidak dapat dikontrol. Faktorfaktor tersebut mempengaruhi perubahan data harga saham sehingga karakteristik data menjadi tidak jelas dan tidak pasti. Oleh karena itu, dalam penelitian ini digunakan SVM untuk mengolah data yang tidak pasti dan memiliki dimensi tinggi dengan cara menerapkan kernel function untuk meningkatkan akurasi model peramalan. Penelitian menunjukkan bahwa SVM memberikan hasil yang lebih baik daripada ARIMA.

Peramalan harga saham dengan menggunakan SVM terus dikembangkan seperti pada penelitian Abolhassani dan Yaghoobi (2010) yang melakukan peramalan New York Stock Exchange dengan mengintegrasikan Support Vector Machine dan Particle Swarm Optimization. Pada penelitian tersebut indikator yang bervariasi dari analisis teknikal digunakan sebagai input, seperti korelasi antara harga saham dari perusahaan yang berbeda yakni DJI, S\&P 500 dan Nasdaq-100. Particle Swarm Optimization (PSO) digunakan untuk memilih input yang paling informatif dari semua indikator analisis teknikal. Hasil penelitian menunjukkan bahwa konsep korelasi dan penggunaan PSO mampu meningkatkan kinerja SVM secara signifikan. PSO juga dapat dikombinasikan dengan Type2 Fuzzy Time Series. Kombinasi metode tersebut diaplikasikan pada penelitian yang dilakukan Singh dan Borah (2014) pada perusahaan Google untuk menyesuaikan panjang interval dalam peramalan tanpa meningkatkan jumlah interval. Hasil penelitian menunjukkan bahwa akurasi peramalan model dapat ditingkatkan secara efektif dengan hibridisasi PSO dan Type2 Fuzzy Time melalui utilisasi frekuensi interval bobot dengan defuzifikasi.

Metode lain yang digunakan untuk mengakomodasi kekurangan ARIMA adalah metode peramalan modern Jaringan Saraf Tiruan (JST). Kombinasi ARIMA dengan JST diaplikasikan pada penelitian Ratyanaka et al. (2015) dalam melakukan peramalan Colombo Stock Exchange yang memiliki pola data tidak stabil dan fluktuasi yang bergejolak tinggi. Peramalan pertama dilakukan dengan menerapkan ARIMA dan JST secara terpisah. Pada tahap berikutnya, dilakukan peramalan dengan mengintegrasikan ARIMA dengan JST. Dari kedua tahap penelitian tersebut, didapatkan bahwa metode yang diintegrasikan memberikan solusi terbaik untuk memprediksi harga saham dengan fluktuasi data yang bergejolak tinggi dibandingkan dengan metode yang diterapkan secara terpisah. Pada penelitian lain yang dilakukan oleh Nugraha 
dan Azhari (2014) dalam meramalkan tingkat inflasi di Indonesia, digunakan JST sebagai metode peramalan. Berdasarkan penelitian tersebut didapatkan masalah overfitting saat proses pembelajaran JST dengan menggunakan algoritma Backpropagation sehingga akhirnya tidak dapat mengeneralisasi masalah. Oleh karena itu, maka perlu dilakukan kombinasi suatu metode lain untuk mengatasi kekurangan JST, salah satunya yaitu Particle Swarm Optimization yang merupakan salah satu metode Artificial Intelligence terbaik untuk optimasi dan perkiraan parameter (Neto et al., 2009). Dengan menggunakan PSO maka akan membantu proses pembelajaran pada JST.

Berdasarkan uraian beberapa penelitian di atas dapat ditarik kesimpulan bahwa penelitian peramalan harga saham terus dikembangkan. Penelitian dilakukan dengan mengkombinasikan beberapa metode untuk saling melengkapi kekurangan dari setiap metode yang diterapkan. Pada penelitian ini, peneliti akan melakukan peramalan Indeks Harga Saham Gabungan dengan mengkombinasikan Jaringan Saraf Tiruan dan Particle Swarm Optimization.

\section{Metode}

Objek penelitian yang digunakan adalah data Indeks Harga Saham Gabungan pada Maret 2016 sampai Februari 2017. Dari empat jenis harga pasar pada indeks harga saham, data yang digunakan untuk melakukan peramalan adalah harga penutupan karena harga ini merupakan harga yang dapat dijadikan acuan untuk memprediksi harga pembuka di hari berikutnya sehingga membantu dalam mempertimbangkan keputusan investasi. Data selanjutnya akan dibagi menjadi dua kelompok yaitu data untuk pelatihan dan pengujian model dengan komposisi $60 \%$ data untuk pelatihan dan $40 \%$ data untuk pengujian model. Tahapan pertama dalam pembangunan model adalah menentukan arsitektur dan parameter model. Arsitektur yang dibutuhkan untuk membuat JST adalah jumlah layer dan neuron di input, hidden, dan output layer sedangkan parameter yang dibutuhkan meliputi learning rate dan momentum. Adapun parameter pada
Particle Swarm Optimization (PSO) yaitu jumlah partikel dan konstanta learning factor 1 dan learning factor 2. Masing-masing parameter JST dan PSO dicari menggunakan Design of Experiment dan analisis regresi sehingga diperoleh kombinasi parameter yang optimal. Setelah arsitektur dan parameter model ditentukan, tahapan selanjutnya adalah membangun model. Terdapat dua model yang dibuat, yaitu model JST dengan menggunakan algoritma pembelajaran Backpropagation (BP) dan model JST yang dikombinasikan dengan metode metaheuristik PSO. Model BP digunakan untuk pelatihan dan pengujian data sedangkan model kombinasi BP dan PSO hanya digunakan untuk pelatihan data. Model yang dibangun selanjutnya dilakukan validasi untuk membandingkan hasil yang diperoleh dari model dengan kondisi nyata sehingga dapat diketahui apakah model yang dibuat memberikan error yang kecil atau tidak. Validasi dilakukan pada tahap proses pengujian, kemudian data hasil pengujian dibuat tracking signal untuk melihat persebaran error masih dalam batas kendali atau tidak. Setelah model dinyatakan valid, selanjutnya dijalankan untuk mendapatkan hasil peramalan indeks harga saham. Hasil run dari dua model dibandingkan berdasarkan waktu dan nilai error untuk mengetahui model yang memberikan hasil peramalan yang lebih akurat.

\section{HASIL DAN PEMBAHASAN Analisis Data}

Berdasarkan pola datanya harga penutupan IHSG membentuk pola tren naik seperti terlihat pada Gambar 1. Adanya pola tren memberikan efek yang tidak diinginkan pada kinerja prediksi Jaringan Saraf Tiruan (Tseng $d k k$., 2002). Oleh karena itu, pola tren naik harga penutupan IHSG diubah menjadi pola stasioner dengan melakukan differencing.

Dari hasil differencing selanjutnya dilakukan identifikasi data berdasarkan laglag signifikan pada partial autocorrelation function (PACF) atau plot fungsi autokorelasi parsial untuk menentukan input dan target. Hasil plot fungsi autokorelasi menunjukkan 
bahwa lag yang signifikan adalah lag 29 dan lag 60, sehingga kedua lag tersebut masingmasing akan dijadikan sebagai input 1 dan input 2 pada arsitektur jaringan.

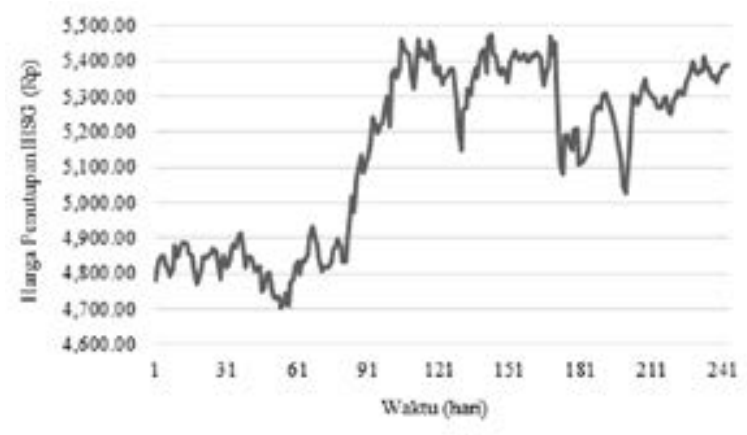

(i)

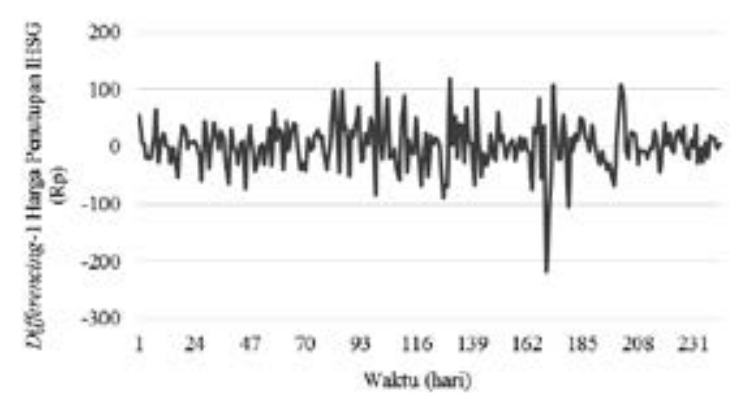

(ii)

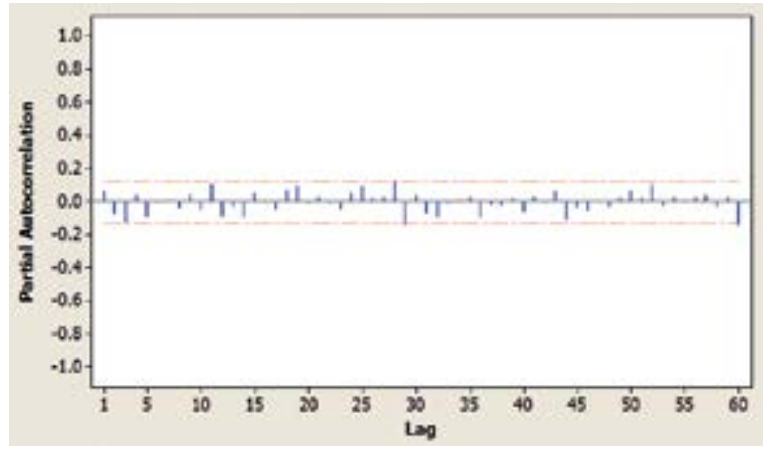

(iii)

Gambar 1

Pola Data (i) Harga Penutupan IHSG Maret 2016-Februari 2017; (ii) Differencing-1; (iii) Autokorelasi Parsial Data Differencing-1

Data input dan target yang telah didapatkan kemudian dinormalisasi agar data berada pada suatu range tertentu sehingga tidak terdapat dominasi data yang bernilai besar terhadap data yang bernilai kecil dan untuk memfasilitasi proses pembelajaran jaringan.

\section{Model Jaringan Syaraf Tiruan - Back Propagation}

Peramalan IHSG dengan metode Jaringan Saraf Tiruan akan dilakukan dengan algoritma pembelajaran Backpropagation (BP). Algoritma ini akan melakukan pembelajaran terhadap input dan target dengan melakukan adaptasi sesuai parameter-parameter yang telah ditentukan. Proses pembuatan model peramalan dengan menggunakan metode Jaringan Saraf Tiruan diawali dengan menyusun arsitektur dan parameter Backpropagation. Arsitektur Backpropagation terdiri dari jumlah layer dan jumlah neuron pada input, hidden, dan output layer. Arsitektur yang dibuat pada penelitian ini terdiri dari 2 input layer dengan 183 neuron, 1 hidden layer dengan $k$ neuron, dan 1 output layer dengan 183 neuron.

Parameter Backpropagation terdiri dari jumlah epoch, learning rate, momentum, toleransi atau error goal, fungsi pelatihan, dan fungsi aktivasi. Penyusunan parameter dalam membuat model peramalan bertujuan untuk mendapatkan bobot yang optimal untuk setiap layer. Pada penelitian ini dilakukan Design of Experiment (DOE) untuk menentukan kombinasi parameter yang sesuai untuk mendapatkan bobot yang optimal. DOE dilakukan terhadap beberapa parameter yang sangat berpengaruh pada optimasi bobot dengan algoritma Backpropagation yaitu learning rate, momentum dan jumlah neuron di hidden layer (Hsu, 2011). Dalam penyusunan DOE digunakan tiga level (low, medium, high) yang berarti terdapat $3^{\mathrm{n}}$ factorial design, maka ada 27 design kombinasi parameter. Untuk algoritma Backpropagation, level DOE diambil dari beberapa hasil penelitian yaitu Jabin (2014), Chen $d k k_{., .}$(2013), dan Hsieh $d k k_{.,}$. (2011) setelah diuji terlebih dahulu. Tabel 1. merupakan level DOE untuk parameter BP. 
Tabel 1.

Level DOE Parameter Backpropagation

\begin{tabular}{c|l|l|l}
\hline \multirow{2}{*}{\multicolumn{1}{c|}{ Parameter }} & \multicolumn{3}{c}{ Level } \\
\cline { 2 - 4 } & Low & Medium & High \\
\hline $\begin{array}{l}\text { Jumlah neuron di } \\
\text { hidden layer (nH) }\end{array}$ & 1 & 6 & 9 \\
\hline Learning rate (a) & 0,25 & 0,40 & 0,60 \\
\hline Momentum (Mc) & 0,20 & 0,40 & 0,95 \\
\hline
\end{tabular}

Berdasarkan analisis DOE didapatkan parameter optimal untuk algoritma Backpropagation yaitu jumlah neuron di hidden layer sama dengan 1, learning rate 0,6 dan momentum 0,2 .

Setelah mendapatkan nilai parameter optimal, langkah selanjutnya adalah menjalankan proses pelatihan untuk memperoleh bobot yang optimal dengan menggunakan parameter yang telah didapatkan dari tahap sebelumnya. Adapun beberapa parameter lain nilainya diatur tetap berdasarkan karakteristik jaringan yang akan dibuat. Tabel 2. menunjukkan semua parameter yang akan digunakan untuk membuat model.

Tabel 2.

Parameter Pelatihan Menggunakan Backpropagation

\begin{tabular}{l|l}
\hline \multicolumn{1}{c|}{ Parameter } & \multicolumn{1}{c}{ Spesifikasi } \\
\hline Arsitektur jaringan & 1 hidden layer \\
\hline Inisialisasi bobot & Nilai acak \\
\hline $\begin{array}{l}\text { Fungsi aktivasi ke hidden } \\
\text { layer }\end{array}$ & Sigmoid bipolar \\
\hline $\begin{array}{l}\text { Fungsi aktivasi ke } \text { output } \\
\text { layer }\end{array}$ & Linier \\
\hline Fungsi pelatihan & Traingd \\
\hline Learning rate & 0,6 \\
\hline Momentum & 0,2 \\
\hline Jumlah iterasi (epoch) & 60000 \\
\hline Toleransi (MSE) & 0,0035 \\
\hline
\end{tabular}

Berdasarkan pelatihan dengan Backpropagation, diperoleh hasil MSE 0,0031 dengan waktu komputasi selama 4,9927 detik serta bobot input 1 dan 2 ke hidden layer masingmasing -0,7890 dan 0,0147, bobot hidden ke output layer -1,4202 dan bias pada hidden dan output layer masing-masing -0,2166 dan -0,2723.

Setelah proses pelatihan selanjutnya dilakukan pengujian model dengan menggunakan $40 \%$ data yang belum digunakan dalam proses pelatihan dengan menggunakan bobot yang telah didapatkan dari hasil pelatihan dan diperoleh MSE pengujian sebesar 0,0131. Gambar 2 menunjukkan hasil pelatihan dan pengujian model.

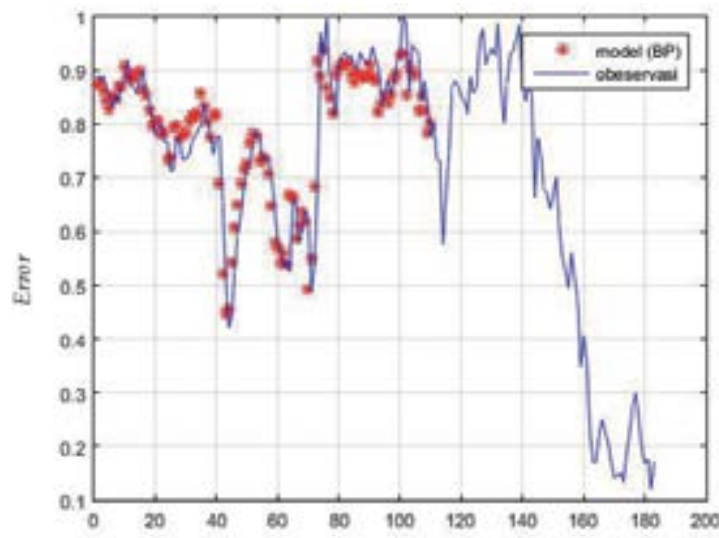

Hasil Pengujian (i)

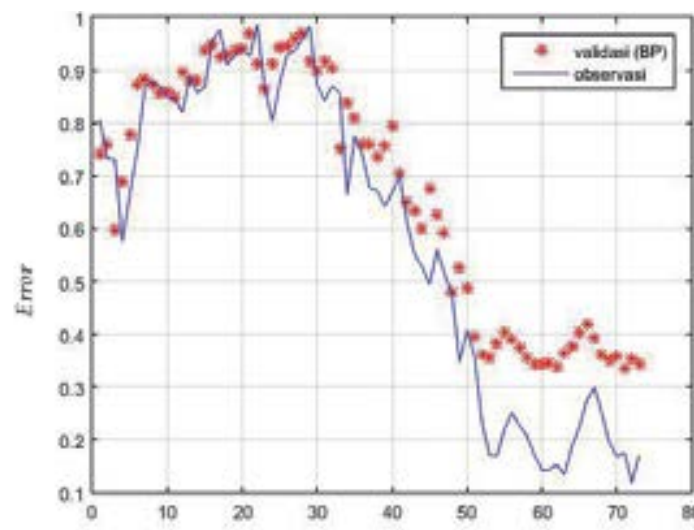

Hasil Pengujian (ii)

Gambar 2.

Hasil (i) Pelatihan dan (ii) Pengujian Menggunakan Bobot dari BP

\section{Model Jaringan Syaraf Tiruan - BP+Particle Swarm Optimization}

Model yang dibuat dengan algoritma Particle Swarm Optimization (PSO) menggunakan parameter Particle Swarm Optimization dan arsitektur jaringan dari algoritma Back- 
propagation. Proses pembuatan model peramalan dengan menggunakan algoritma Particle Swarm Optimization diawali dengan menentukan parameter PSO. Parameter Particle Swarm Optimization terdiri dari bobot inersia, jumlah partikel, dan learning factor. Penyusunan parameter dalam membuat model peramalan bertujuan untuk mendapatkan bobot yang optimal untuk setiap layer. Pada penelitian ini dilakukan Design of Experiment (DOE) untuk menentukan kombinasi parameter yang sesuai untuk mendapatkan bobot yang optimal. DOE dilakukan terhadap beberapa parameter yang sangat berpengaruh pada optimasi bobot dengan algoritma Particle Swarm Optimization yaitu jumlah partikel dan learning factor. Dalam penyusunan DOE digunakan 3 level (low, medium, high) yang berarti terdapat $3^{\text {n }}$ factorial design, maka ada 27 design kombinasi parameter. Untuk algoritma Particle Swarm Optimization, level DOE diambil dari beberapa hasil penelitian yaitu Asriningtias et al. (2015), dan Deng et al. (2016) setelah diuji terlebih dahulu. Parameter optimal untuk algoritma Particle Swarm Optimization yaitu jumlah partikel sama dengan 11, learning factor 11,3 dan learning factor 21,5.

Setelah menentukan parameter optimal, tahap selanjutnya adalah melakukan pelatihan data. Proses pelatihan dilakukan untuk membuat model Particle Swarm Optimization dengan menggunakan parameter optimal yang telah didapatkan. Tabel 2. menunjukkan semua parameter yang akan digunakan untuk membuat model.

Tabel 3. Parameter Pelatihan Menggunakan Particle Swarm Optimization

\begin{tabular}{l|l}
\hline \multicolumn{1}{c|}{ Parameter } & \multicolumn{1}{c}{ Spesifikasi } \\
\hline Jumlah partikel & 11 \\
\hline Learning factor 1 & 1,3 \\
\hline Learning factor 2 & 1,5 \\
\hline Posisi awal partikel & Nilai acak \\
\hline Kecepatan awal partikel & Nilai acak \\
\hline Bobot inersia awal & Nilai acak \\
\hline Bobot inersia minimum & 0,4 \\
\hline Bobot inersia maksimum & 0,9 \\
\hline Jumlah iterasi & 20 \\
\hline
\end{tabular}

Setelah memasukkan semua parameter pada pelatihan jaringan, dilakukan pelatihan terhadap $60 \%$ data input dan target. Berdasarkan pelatihan dengan Particle Swarm Optimization, diperoleh hasil MSE 0,0030 dengan waktu komputasi selama 4,3867 detik serta bobot input layer 1 dan 2 ke hidden layer masing-masing -2,1027 dan 0,2994, bobot hidden ke output layer -1,8687 dan bias pada hidden dan output layer masing-masing 0,1801 dan 1,1444. Hasil pelatihan dapat dilihat pada Gambar 3(i).

Setelah proses pelatihan selanjutnya dilakukan pengujian model dengan menggunakan $40 \%$ data yang belum digunakan dalam proses pelatihan dengan menggunakan bobot yang telah didapatkan dari hasil pelatihan dan diperoleh MSE pengujian sebesar 0,0062. Gambar 3(ii) menunjukkan hasil pengujian model.
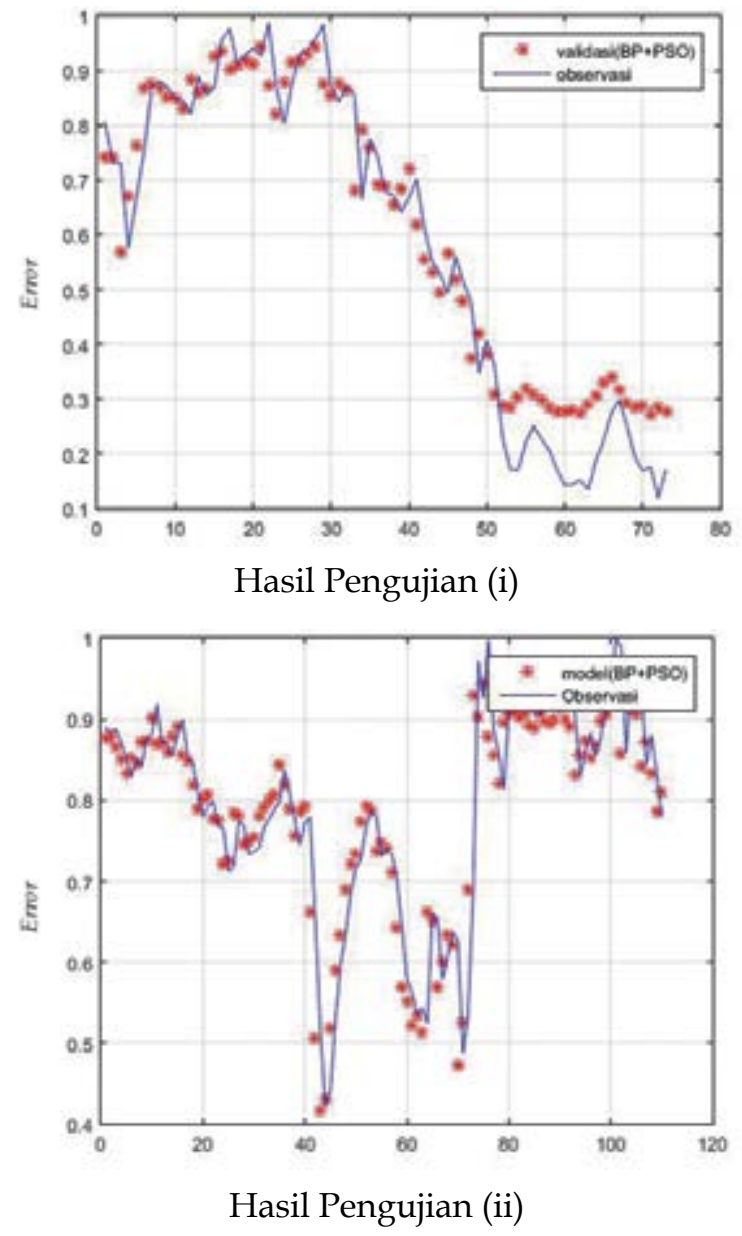

Gambar 3.

Hasil (i) Pelatihan dan (ii) Pengujian Menggunakan Bobot dari BP-PSO 


\section{Peramalan Out Sample}

Berdasarkan dua model peramalan yang telah dibuat, yaitu dengan algoritma Backpropagation dan algoritma Particle Swarm Optimization, dilakukan perbandingan terhadap hasil yang didapatkan, yaitu waktu komputasi dan error yang dihasilkan. Perbandingan hasil dari kedua model peramalan dapat dilihat pada Tabel 4 .

Tabel 4

Perbandingan Hasil BP dan Kombinasi BP dengan PSO

\begin{tabular}{l|l|l|l|l}
\hline & $\begin{array}{c}\text { Waktu Komputasi } \\
\text { Proses Pelatihan (detik) }\end{array}$ & $\begin{array}{c}\text { MSE Proses } \\
\text { Pelatihan }\end{array}$ & $\begin{array}{c}\text { MSE Proses } \\
\text { Pengujian }\end{array}$ & $\begin{array}{c}\text { MAPE Hasil } \\
\text { Peramalan (\%) }\end{array}$ \\
\hline BP & 4,9927 & 0,0031 & 0,0131 & 2,5472 \\
\hline BP dengan PSO & 4,3867 & 0,0030 & 0,0062 & 1,8823 \\
\hline
\end{tabular}

Melalui hasil yang didapatkan untuk kedua model, dapat diketahui bahwa model yang dibuat dengan kombinasi algoritma BP dan PSO menghasilkan waktu komputasi, error model, dan error peramalan yang lebih kecil daripada model BP. Apabila dilihat dari nilai MAPE, peramalan yang dilakukan dengan kedua model tersebut termasuk highly accurate karena MAPE yang dihasilkan lebih kecil daripada 10\%. Oleh karena itu, kedua model BP dan kombinasi BP dengan PSO dapat digunakan untuk melakukan peramalan IHSG, akan tetapi perlu dilakukan pengaturan parameter yang berbeda karena akan menentukan performa algoritma terhadap kasus yang diselesaikan.

\section{SIMPULAN}

Peramalan indeks harga saham Bursa Efek Indonesia, telah berhasil dibuat model peramalan IHSG menggunakan metode Jaringan Saraf Tiruan (JST) dengan algoritma Backpropagation (BP) dan algoritma Backpropagation yang dikombinasikan dengan algoritma Particle Swarm Optimization (PSO). Pembuatan model dilakukan dengan mengatur parameter yang telah disesuaikan untuk mendapatkan hasil waktu komputasi, error model dan error peramalan yang minimal. Melalui analisis yang telah dilakukan pada bab hasil dan pembahasan, didapatkan model BP dengan PSO menghasilkan waktu komputasi dan error model yang lebih kecil daripada model BP yaitu 4,3867 detik dengan MSE proses pelatihan dan pengujian masing-masing 0,0030 dan 0,0062. Berdasarkan hasil tersebut, diperoleh bahwa model BP dengan PSO memberikan hasil yang lebih baik dibandingkan model BP. Adapun peramalan yang dilakukan dengan kedua model tersebut termasuk highly accurate karena MAPE yang dihasilkan lebih kecil daripada $10 \%$ yaitu 2,55\% untuk BP dan $1,88 \%$ untuk BP dengan PSO.

\section{DAFTAR PUSTAKA}

Abdulmajeed, A.A., Narhi, T.O., Vallitu, P.K., and Lassila L.V., 2011, The Effect of High Fiber Fraction on Some Mechanical Properties of Unidirectional Glass Fiber-Reinforced Composite. J. Dent. Materials. 27 :313-321.

Abolhassani, A.T., dan Yaghoobi, M., 2010, Stock Price Forecasting Using PSO SVM, Advanced Computer Theory and Engineering, pp. 352-356.

Adebiyi, A.A., Adewumi, A.O., dan Ayo, C.K., 2014, Stock Price Prediction Using The ARIMA Model, Computer Society, pp. 106-112.

Asriningtias, S.R., Dachlan, H.S., dan Yudaningtyas, E., 2015, Optimasi Training Neural Network Menggunakan Hybrid Adaptive Mutation PSO-BP, Jurnal Electrics, Electronics, Communications, Controls, Informatics, Systems , 9(1), pp. 79-84.

Banarjee, D., 2014, Forecasting of Indian Stock Market Using Time-Series ARIMA Model, Business and Information Management, pp. 131-135.

Chen, C.H., 1994, Neural Networks for Financial Market Prediction, Neural Networks, 2, pp. 1199-1202. 
Chen, M.Y., Fan, M.H., Chen, Y.L., dan Wei, H.M., 2013, Design of Experiments on Neural Network's Parameters Optimization for Time Series Forecasting in Stock Markets, Neural Network World, 23(4), pp. 369-393.

Cortes, C. dan Vapnik, V., 1995, Support Vector Networks, Machine Learning, 20(3), pp. 273-295.

Deng, W., Wang, G., Zhang, X., Xu, J., dan Li, G., 2016, A Multi-Granularity Combined Prediction Model Based on Fuzzy Trend Forecasting and Particle Swarm Techniques, Neurocomputing, 173(3), pp. 1671-1682.

Devi, K.N., Bhaskaran, V.M., dan Kumar, G.P., 2015, Cuckoo Optimized SVM for Stock Market Prediction, 2015 International Conference on Innovations in Information, Embedded and Communication Systems Proceedings, pp. 1-5.

Hsieh, L.F., Hsieh, S.C., dan Tai, P.H., 2011, Enhanced Stock Price Variation Prediction Via DOE and BPNN-based Optimization, Expert Systems with Application, 38(11), pp. 14178-14184.

Hsu, C.M., 2011, Forecasting Stock/Futures Prices by Using Neural Networks with Feature Selection, International Information Technology and Artificial Intelligence 2011 Conference Proceedings, pp. 1-7.

Jabin, S., 2014, Stock Market Prediction Using Feed-forward Artificial Neural Network, International Journal of Computer Applications, 99(9), pp. 4-8.

Khirbat, G., Gupta, R., dan Singh, S., 2013, Optimal Neural Network Architecture for Stock Market Forecasting, Communication Systems and Network Technologies 2013 Proceedings, pp. 557-561.

Kurniawati, L.Y., Tjandrasa, H., dan Arieshanti,I.,2013,PrediksiPergerakan Harga Saham Menggunakan Support Vector Regression, Jurnal Teknologi Informasi dan Komunikasi, 8(2), pp. 11-21.
Kustodian Sentral Efek Indonesia, 2016, Raih Rekor Baru, Jumlah Investor Tercatat Naik 26\%, http://www.ksei.co.id, (diakses 16 Desember 2016).

Neto,M.,Petry, G.G., Aranildo, R.L., danFerreira, T.A., 2009, Combining Artificial Neural Network and Particle Swarm System for Time Series Forecasting, International Joint Conference on Neural Networks, pp. 2230-2237.

Nugraha, H.G., dan Azhari, S.N., 2014, Optimasi Bobot Jaringan Saraf Tiruan Menggunakan Particle Swarm Optimization, Indonesian Journal of Computing and Cybernetics Systems, 8(1), pp. 25-36.

Ratyanaka, R.M.K.T., Seneviratne, D.M.K.N., Jianguo, W., dan Arumawadu, H.I., 2015, A Hybrid Statistical Approach for Stock Market Forecasting Based on Artificial Neural Network and ARIMA Time Series Models, Behavioral, Economic, and Socio-Cultural Computing, pp. 54-60.

Sadono, Y.A.,2016, BEI:JumlahInvestor PasarModal Domestik Mencapai 500.037, http:// www.antaranews.com/berita/584991/ bei-jumlah-investor-pasar-modaldomestik-mencapai-500037, (diakses 4 Desember 2016).

Singh, P., dan Borah, B., 2014, Forecasting Stock Index Price Based on M-factors Fuzzy Time Series and Particle Swarm Optimization, International Journal of Approximate Reasoning, 55(3), pp. 812-833.

Sirijunyapong, W., Leelasantitham, A., Kiattisin, S., dan Wongseree, W., 2014, Predict The Stock Exchange of Thailand-Set, Information and Communication Technology,Electronic and Electrical Engineering, pp. 978-982.

Tseng, F.M., Yu, H.C., dan Tzeng, G.H., 2002, Combining Neural Network Model with Seasonal Time Series ARIMA Model, Technological, Forecasting, and Social Change, 69(1), pp. 71-87. 